\title{
Sustainable Biofuels and Other Related Bio-Products from Palm Cultivations
}

\author{
Farid Nasir Ani \\ Department of Thermodynamics and Fluid Mechanics, Faculty of Mechanical Engineering, Universiti Teknologi Malaysia, UTM 81310, \\ Skudai, Johor Bahru, Malaysia
}

\begin{abstract}
Various kinds of palm trees are grown in the tropical regions of the world that provide edible oils for food consumption. They have in common in providing edible oils from the nuts and some from the mesocarp such as oil palm. More than 400 mills in Malaysia have provided more than sufficient energy from the biomass in processing the fruits to crude palm oil. The biomass are the mesocarp fibres, shells or endocarp, empty fruit bunches and palm oil mill effluents. One option of treatment of this biomass is to convert into bio-oil, bio-char, bio-adhesives and methyl ester. Recent research using microwave processing of biomass and biodiesel are given in this paper.
\end{abstract}

\section{Introduction}

Cultivated palm plantation produces biomass from their processing mills plays an important role in the daily activities in producing the food commodities. Generally, biomass also provides flexibility in shifting usage from food to energy and to material applications whenever needed, and has been well been demonstrated at large scale production. This paper describes the recent work on four possible routes to provide energy and other related products from biomass. The products are bio-oil, bio-char, methyl ester (B100) and biolubricants. These products can be further converted into a range of finer products with several other conversion processes.

\section{Oil palm biomass availability and characteristic}

The palm oil mills and its plantations produces the enormous amount of biomass that includes empty fruit bunches (EFB), shells (OPS), fibers (OPF), effluents (POME), trunks and fronds. In year-end 2012, the palm oil mills generated approximately 95.21 million tonnes of oil palm waste of which comprises of EFB, 21.90, OPF 12.38, OPS 5.71, POME 55.22 mtonnes, [1]. The composition of OPS are 31.0 cellulose, 20.0 hemicellulose and 49.0 lignin, OPF are 40.0 cellulose, 39.0 hemicellulose and 21.0 lignin and EFB are 40.0 cellulose, 36.0 hemicellulose and 24.0 lignin, [2].

Ag Agricultural wastes are usually of high moisture content and low in bulk density and consequently have relatively low calorific values. The chemical and physical characteristics of oil palm biomass are presented in Table $1 \mathrm{a}, 1 \mathrm{~b}$ and $1 \mathrm{c}$. The range for the oxygen content of biomass is $38-45 \%$ on moisture and ash free basis. The result of high oxygen content leads to relatively low calorific value of $14-20 \mathrm{MJ} / \mathrm{kg}$.

Table 1a. Typical analysis of oil palm biomass.

\begin{tabular}{|c|c|c|c|c|}
\hline \multirow{2}{*}{ Material } & \multicolumn{4}{|c|}{$\begin{array}{c}\text { Elemental composition \% wt } \\
\text { (dry ash free) }\end{array}$} \\
\cline { 2 - 5 } & C & H & N & O \\
\hline Shells & 55.35 & 6.27 & 0.37 & 38.01 \\
\hline Fibers & 52.89 & 6.43 & 1.08 & 39.6 \\
\hline Bunches & 47.89 & 6.05 & 0.65 & 45.41 \\
\hline
\end{tabular}

Table 1b. Typical analysis of oil palm biomass.

\begin{tabular}{|c|c|c|c|c|}
\hline \multirow{2}{*}{ Material } & \multicolumn{4}{|c|}{$\begin{array}{c}\text { Proximate analysis \% wt } \\
\text { (air dry) }\end{array}$} \\
\cline { 2 - 5 } & $\mathbf{C}$ & H & N & O \\
\hline Shells & 55.35 & 6.27 & 0.37 & 38.01 \\
\hline Fibers & 52.89 & 6.43 & 1.08 & 39.6 \\
\hline Bunches & 47.89 & 6.05 & 0.65 & 45.41 \\
\hline
\end{tabular}

Table 1c. Typical analysis of oil palm biomass.

\begin{tabular}{|c|c|c|}
\hline Material & $\begin{array}{c}\text { Gross C.V. } \\
\text { MJ kg }^{-1}\end{array}$ & $\begin{array}{c}\text { Ave. bulk } \\
\text { density } \\
\text { kg m }^{-3}\end{array}$ \\
\hline Shells & 19.56 & $\begin{array}{c}440 \\
(\text { size }<18 \mathrm{~mm})\end{array}$ \\
\hline Fibers & 19.15 & - \\
\hline Bunches & 17.83 & - \\
\hline
\end{tabular}

\subsection{Bio-oil initiative}

The interest on fast pyrolysis at UTM using fluidized bed reactor was developed with capacity of $0.6-1.0 \mathrm{~kg} / \mathrm{h}$ was initiated in early 1990s, [3]. Later, a $6 \mathrm{~kg} / \mathrm{h}$ continuous fast pyrolysis rig was designed, fabricated and operated, 
[4]. In 2005, Genting Sanyen Bhd, using BTG technology, installed a commercial rotating cone pyrolysis plant which runs on EFB with capacity of $2000 \mathrm{~kg} / \mathrm{h}$ were operated in Malaysia, [5]. Salema and Ani [6] used microwave assisted pyrolysis of OPS and OPF with different bio-char ratio. The use of bio-char with OPS and OPF was found to initiate the pyrolysis conditions. It concluded that the low microwave technique gave significant energy saving route for bio-oil production. Abubakar introduced an overhead stirrer in the MW pyrolysis technique to reduce bio-oil deposition problem within MW reactor, [7]. The inert gas is supplied from the top side of the reactor and subsequent quenching of the vapors at the bottom side with vertical condensers. The phenols content was found much higher with $85 \%$ under GC-MS area. Ani, Salema and Hassan characterized and compared the pyrolysis bio-oil from OPS and EFB using various pyrolysis techniques. The phenolic yield in bio-oils was found to be dependent on the process temperature. The OPS bio-oil produced higher fractions of phenol and its compounds, as compared to EFB bio-oil [8].

\subsubsection{Bio-oil properties}

In general, bio-oil is dark brown in colour and usually slightly heavier than water with high viscosity at room temperature. The energy content of the bio-oil obtained ranges from 16.25 to $22.5 \mathrm{MJ} / \mathrm{kg}$. This value has lower heating value than fuel oil due to the presence of some highly oxygenated components in the bio-oil. Bio-oil has high acidity, $\mathrm{pH}$ of 2.42 as a result of acetic and formic acids contents. It has low pour point and high flash point due to the existence of low boiling volatile compounds with a considerably high amount. Bio-oil from oil palm shells consists of significantly high fraction of phenol and phenolic compounds, with concentrations up to 50.54 area $\%$ and 22.21 area $\%$ respectively. Bed temperature was found to be the key parameter affecting the phenol and phenolic compounds. The bio-oil is complex mixtures of various chemical compounds. Almost 50 kinds of major chemical compounds were identified from the OPS bio-oil samples from which only important components. The phenol percentage in the OPS bio-oil for second study was higher (50 wt\%) compared to earlier work which was about $22 \mathrm{wt} \%$ at $490^{\circ} \mathrm{C}$.

The phenolic concentrations in bio-oil vary from various pyrolysis technics. The content of phenol from MW pyrolysis system was found to be the highest of about 62 area \% in case of EFB and 84 area \% in case of OPS. Basically, the process condition associated with the pyrolysis technologies can affect the formation of chemical compounds in the bio-oil, particularly, the bed temperature. The EFB bio-oils obtained from fluidized bed also contained a high amount of phenolic compounds, [9]. It was interesting to find that high amount of phenol can be obtained through MW pyrolysis without any prior treatment of EFB biomass.
Bio-oil contains phenol and phenolic compounds which could be used in fine chemicals, pharmaceuticals, food favourings and biopolymers. Recent research on the utilisation of OPB bio-oil as resins and adhesives were conducted by Md Kawser and Ani [10], Wong and Ani [11], Wong and Ani [12], Lai, Ani and Hassan [13]. The bio-oil from the earlier work was extracted using solvent extraction technique to gain the useful phenol and phenolic compounds. The extracted oil-palm-shell-based phenol was used in the manufacture of phenol formaldehyde wood adhesives. It was found that, the wood bonding performances between petroleum-based adhesives and the oil-palm-shell-based adhesives, were comparable and acceptable. Wong and Ani [12]. Abubakar, Salema and Ani [7] produces phenol rich ( $85 \%$ area) bio-oil from OPS using microwave assisted pyrolysis and suggested that it could be used directly for resin and adhesives application. Recently, Choi et. al. suggested that bio-oil can typically substitute for fossil phenol but, the main concern in the production of phenolic resins, appears to be the substitution level of bio-oil for fossil phenol [14].

In general, bio-oil is dark brown in colour and usually slightly heavier than water with high viscosity at room temperature. The energy content of the bio-oil obtained ranges from 16.25 to $22.5 \mathrm{MJ} / \mathrm{kg}$. This value has lower heating value than fuel oil due to the presence of some highly oxygenated components in the bio-oil. Bio-oil has high acidity, $\mathrm{pH}$ of 2.42 as a result

\section{Oil palm biochar activities}

The reflection, absorber and dielectric properties of oil palm bio-char and their composites are given in Ani et. al. [15], Yusof et. al. [16] and Salema et. al. [17]. The comparison of BET surface area between microwave and conventional heating was studied by Abas and Ani [18]. It shows that biochar produced via microwave heating technique has higher quality as compared to conventional heating pyrolysis in which significant cracks and fissure due to convective heating profiles and differences in temperature of outer and inner surfaces which leads to more fragile biochar.

The observation of BET surface area of biochar produced from microwave heating system was investigated by Guo and Lua, [19], Salema and Ani [20] and Foo and Hameed, [21]. The highest surface area $\left(255.7 \mathrm{~m}^{2}\right.$.f ( v hog 'udq fd onqd rhyd ne 11-21@ was detected from biochar from EFB which observed by Foo and Hameed, [21]. It should be noted that, the surface area of biochar produced from OPF via microwave heating which was $205.21 \mathrm{~m}^{2} / \mathrm{g}$, much lower than conventional heating [21] and it was observed that the lowest surface area of $194.3 \mathrm{~m}^{2} / \mathrm{g}$ was detected in biochar from OPS by Guo and Lua, [19].

\subsection{Activated carbon}

The quality of biochar is enhanced using a physical activation after carbonation process. The applications of 
activated carbon are numerous, from air cleaning to water treatment. Both processes of carbonation and activation could be done using microwave assisted process with temperature ranging up to $900{ }^{\circ} \mathrm{C}$. The temperature in the reactor was closely controlled by a temperature controller [22]. Studies show that chemical activation give higher BET surface areas using less MW power. Also, despite using lower MW power, other parameters also contributed signicantly to the development of the porosity in the activated carbon, such as activated time, temperature, impregnation ratio and agent.

\subsection{Carbon molecular sieves}

Oil palm shells have been processed to produce microporous carbon adsorbents for air separation [23]. The pore structures of CMS obtained show excellent separation capability of the $\mathrm{O}_{2} / \mathrm{N}_{2}$ selectivity was as high as 48. This kinetic selectivity of air was greatly influenced by the carbonization temperatures, although the micropore surface area and volume were lower and causing less $\mathrm{O}_{2}$ uptake capacity. In another study, $\mathrm{CO}_{2}$ removal from natural gas, biogas and landfill gas which enhance its calorific value, the adsorbents prepared had shown their capability in adsorbing $\mathrm{CO}_{2}$ and $\mathrm{CH}_{4}$ but were more selective towards $\mathrm{CO}_{2}$. It was discovered that the char sample had shown the best molecular sieving effect for the separation of $\mathrm{CO}_{2}$ and $\mathrm{CH}_{4}$ where the selectivity value was the highest in the case for the separation of $\mathrm{CO}_{2}$ from $\mathrm{CH}_{4}$ gas mixture, [22].

\subsection{Methyl ester production}

Palm oil has successfully been processed into palm oil methyl ester. It had been used as B05 commercially in unmodified engines of buses, truck, taxies and cars in Malaysia. The utilization of palm oil as fuel has realized the competition between human needs in food and nonfood applications. It utilization as a renewable source of fuel is a cost factor due to the planting and production cost of the crude oil. In addition, high cost of heating using cogeneration of steam and electrical bring the production cost of methyl ester higher. Thus, an alternative method, microwave irradiation was applied for the production of methyl ester. A continuous transesterification of plant oils was used in a modified microwave oven. The physical properties of waste oil methyl esters met the biodiesel standards.

An average of $2.128 \mathrm{~kW}$ hr of electrical energy could be generated from one $\mathrm{kg}$ of $\mathrm{B} 100$, while the production of one $\mathrm{kg} \mathrm{B} 100$ needs $0.468 \mathrm{kWhr}$ electricity. Thus, there is a potential for production of $1.659 \mathrm{kWhr}$ extra electrical energy per $\mathrm{kg}$ biodiesel which it proves the sustainability of the system. A sustainable processing system was obtained using this system for diesel engines power generation [24]. The analysis was also supported by Choedkiatsakul et al [25], which utilized even lesser energy consumption of $0.1167 \mathrm{kWh} / \mathrm{L}$ of B100.

\subsection{Research in bio-lubricants}

The increase of worldwide concerns about health, the environment and limited petroleum resources has promoted the use of biodegradable and non toxic products for lubricants and hydraulic oils. Animal fats and vegetable oils are considered as renewable substitutes for the mineral-based oil as lubricants. Vegetable oils reveal good lubricating abilities because they produce low coefficients of frictions but has higher wears rate. However, some factors such as the oxidation of vegetable oil must be taken into consideration, Hassan et.al. [26]. In his recent study, he found that the blend of RBD palm olein with mineral engine oil showed good reliability with regard to viscosity parameter. The blend offers better performance because it has a smaller WSD and higher FTP compared to the other oil samples. It had also been proven that the blend reduces material loss of around 48.72 and $41.70 \%$ compared to the neat RBD palm olein and neat mineral engine oil, respectively. Hence, it is proved that this blend has the potential as an antiwear lubricant.

\section{Conclusions}

Palm cultivation holds an important asset for its food sources and other applications from its oil and biomass. However, the choice to use biomass for power, fuel, and biomaterials depends on a variety of factors, such as availability, public policy, cost of biomass, capital cost of processing equipments, infrastructure facilities and markets for alternative energy and materials. The development of advanced conversion technologies such as microwave assisted processing is likely to make biomass both energy and materials products competitive with petroleum-based products. The integrated processing plant of the palm fruits using excess energy for modular processing could be used in the future for the palm mills operation.

\section{Acknowledgement}

The author wishes to acknowledge the MOSTI and the MOHE, Malaysia for the research grants obtained and RMC, UTM for the management support during the course of these studies.

\section{References}

1. GGS (2013) http://www.ggs.my/index.php/palmbiomass (accessed 23rd Oct. 2013).

2. F.N. Ani, Sustainability and Recycling through Thermal Conversion of Bioresources, Professorial Inaugural Lecture Series, Penerbit UTM Press. (2012)

3. M.N. Islam, R. Zailani, and F.N. Ani, Pyrolytic oil from fluidized bed pyrolysis of oil palm shell and its characterisation, Renewable Energy, 17, pp. 73-84 (1999) 
4. X.Y. Lim and F.N. Ani, Continuous Fast Pyrolysis of Oil Palm Shell for Bio-Oil Production, JSPS-VCC Group Seminar 2006, Natural Resources and Energy Environment, 11 -12 December 2006, Johor Bahru, Malaysia, pp 98-106 (2006)

5. R.H. Venderbosch, Gansekoele, E., J.F. Florijn, D. Assink, and H.Y. Ng, Pyrolysis of palm oil residues in Malaysia, PyNe Newsletter, Issue 19, pp. 2-3 (2006)

6. AA. Salema and F.N. Ani, Microwave induced pyrolysis of oil palm biomass, Bioresource Technology, 102 (3), 3388-3395 (2011)

7. Z. Abubakar, AA Salema, F.N. Ani, A New Technique to Pyrolyse Biomass in a microwave system: Effect of Stirrer Speed, Bioresource Technology, 128 (0), 578-585 (2013)

8. F.N. Ani, A.A. Salema, I. Hassan, Bio-oils characteristic from oil palm biomass from different fast pyrolysis techniques. Applied Mechanics and Materials, 554, 266-270 (2014)

9. S.W. Kim, B.S. Koo, J.W. Ryu, J.S. Lee, C.J. Kim, D.H. Lee, G.R. Kim, and S. Choi, Bio-oil from the pyrolysis of palm and Jatropha wastes in a fluidized bed, Fuel Processing Technology. 108, 118-124, 2013-Special Issue of APCRE 11. (2012)

10. J. Md Kawser and F.N. Ani, Oil Palm Shell as a Source of Phenol, Journal of Oil Palm Research, Vol 12, No 1, June, 2000, pp 86-94 (2000)

11. C.C. Wong and F.N. Ani, Properties of Oil Palm Shell Based Phenol Wood Adhesives Compared with Petroleum Based Phenol Wood Adhesives, Journal of Oil Palm Research, PORIM, Vol 16, No 1, June 2004, pp 24-35 (2004)

12. C.C. Wong and F.N. Ani, Feasibility Study on the Potential Production of Oil Palm Shell Bio-Phenol, Oil Palm Industry Economic Journal, Vol 7, No 2, 28-33 (2007)

13. J.C. Lai., F.N. Ani and A. Hassan, Water absorption of lignocellulosic phenolic composites, Polymers and Polymer Composites. 16, 6, p. 379-388 (2008)

14. C. Gyung-Goo, O. Seung-Jin, L. Soon-Jang, K. JooSik, Production of bio-based phenolic resin and activated carbon from bio-oil and biochar derived from fast pyrolysis of palm kernel shells, Bioresource Technology, 178, 99-107 (2015)

15. F.N. Ani, W.K Wan Ali, AA. Yusof, Effect of oil palm shell carb.on-polyester resin composite on microwave absorber properties, Jurnal Mekanikal 19, 1-10 (2005)

16. A.A. Yusof, W.K. Wan Ali, T.A. Rahman, F.N. Ani, Microwave and reflection properties of palm shell carbon-polyester conductive composite absorber (2005)

17. A.A. Salema, Y.K. Yeow, K. Ishaque, F.N. Ani, M.T. Afzal, A. Hassan, Dielectric properties and microwave heating of oil palm biomass and biochar, Industrial Crops and Products 50, 366-374 (2013)

18. F.Z. Abas and F.N. Ani, Comparing characteristics of oil palm biochar using conventional and microwave heating, Jurnal Teknologi (Sciences and Engineering). 68, 3, p. 33-37 (2014)
19. J.Guo, and A. C. Lua.), Preparation Of Activated Carbons from Oil-Palm-Stone Chars By MicrowaveInduced Carbon Dioxide Activation. Carbon 38(14): 1985-1993 (2000)

20. A.A. Salema and F.N. Ani, Microwave-Assisted Pyrolysis of Oil Palm Shell Biomass Using an Overhead Stirrer. Journal of Analytical and Applied Pyrolysis 96:162- 172 (2012)

21. K. Y. Foo, and B. H. Hameed, Microwave-Assisted Preparation of Oil Palm Fiber Activated Carbon for Methylene Blue Adsorption. Chemical Engineering Journal 166(2): 792-795 (2011)

22. J.S. Tan, Preparation of Microporous Carbon Adsorbents from Oil Palm Shell by Physical and Chemical Treatments for Gas Separations, MEng Thesis, Faculty of Mechanical Engineering, Universiti Teknologi Malaysia (2001)

23. J.S. Tan and F. N.Ani, Carbon molecular sieves produced from oil palm shell for air separation, Separation and Purification Technology. 35, 1, p. 47-54 (2004)

24. F. Motasemi and F. N. Ani, A review on microwave-assisted production of biodiesel, Renewable and Sustainable Energy Reviews. 16, 7, p. 4719-4733 (2012)

25. I. Choedkiatsakul, K. Ngaosuwan, S. Assabumrungrat, S. Mantegna, G. Cravotto, Biodiesel production in a novel continuous flow microwave reactor, Renewable Energy, 83, 25-29 (2015)

26. M. Hassan, F.N. Ani, S Syahrullail, Tribological features of refined, deodorized and bleached palm olein with mineral oil blend, Tribology Transactions, $1-8(2015)$ 